Article

\title{
Changing Food Consumption Patterns and Land Requirements for Food in the Six Geopolitical Zones in Nigeria
}

\author{
Jeffrey Chiwuikem Chiaka ${ }^{1,2,3}{ }^{\oplus}$, Lin Zhen ${ }^{1,2, *}$ and Yu Xiao ${ }^{1,2}$
}

1 Key Laboratory for Resources Use and Environmental Remediation, Institute of Geographic Sciences and Natural Resources Research, Chinese Academy of Sciences, Beijing 100101, China; cjchiwuikem2019@igsnrr.ac.cn (J.C.C.); xiaoy@igsnrr.ac.cn (Y.X.)

2 College of Resources and Environment, University of Chinese Academy of Sciences, Beijing 100049, China

3 Anambra-Imo River Basin Development Authority, Agbala 460109, Imo State, Nigeria

* Correspondence: zhenl@igsnrr.ac.cn

Citation: Chiaka, J.C.; Zhen, L.; Xiao, Y. Changing Food Consumption

Patterns and Land Requirements for Food in the Six Geopolitical Zones in Nigeria. Foods 2022, 11, 150. https:// doi.org/10.3390/foods11020150

Academic Editor: Raquel P. F. Guiné

Received: 15 November 2021

Accepted: 27 December 2021

Published: 6 January 2022

Publisher's Note: MDPI stays neutral with regard to jurisdictional claims in published maps and institutional affiliations.

Copyright: (C) 2022 by the authors. Licensee MDPI, Basel, Switzerland. This article is an open access article distributed under the terms and conditions of the Creative Commons Attribution (CC BY) license (https:// creativecommons.org/licenses/by/ $4.0 /)$.

\begin{abstract}
Research on food consumption in Nigeria has mainly focused on food intake, household diversity, and purchasing power. We investigated a knowledge gap for food consumed by households and the land requirements for food resulting from household consumption patterns. The food consumed and the household size determine the land requirement for food. Therefore, a quantitybased analysis and a land demand methodology were applied to derive household food quantity and land requirements for food respectively. The results show that a greater percentage of household income is spent on cereals and starchy roots as the main source of calories and that cowpea is a secondary food option for households. In addition, households are changing their dietary intake from rice to maize and rice to cassava and yams as a cheaper alternative and experts' measurements of food security at the household level indicates that households in our study are moderately food insecure. Other findings show that the country's specific and per capita land requirements for food have gradually increased between 2000 and 2018. Across the six geopolitical zones, Northern regions with higher populations have high land requirements for food, especially for rice and maize (cereals), while Southern regions have high land requirements for cassava and yams (starchy roots) due to their respective consumption and household sizes. In addition, from our study, the land requirements for food show the actual cropland area of South South fed 5000 households. Consequently, a scenario analysis shows that the land requirements for food in our study exceeds the entire geographical area of Nigeria. Therefore, continued population growth without improved living standards and adequate food production output per hectare will further exacerbate food insecurity and land shortage in Nigeria.
\end{abstract}

Keywords: food quantity; food expenditure; food intake; household size; population; Geopolitical Zones in Nigeria

\section{Introduction}

The problem of hunger, poverty and malnutrition in vulnerable countries has continued to attract the attention of various international institutions and humanitarian agencies such as the United Nations World Food Programme (WFP). Sustainable food consumption and production, hunger and poverty reduction are important targets in the United Nations Sustainable Development Goals (SDGs) to be achieved by 2030 [1], and less than a decade before the target, the results so far in many countries are not encouraging [2,3]. The need to address the above issues stems from expert reports and studies which highlighted the global malnutrition burden and risk of hunger as a result of the overarching effect of low calorie consumption, low self-sufficiency and a lack of food diversity seen especially in developing countries, which are exacerbated by climate change, low income, low food production and lack of food access [4,5]. In addition, the advent of COVID-19, which has 
disrupted the global and national food supply chain, has added to the list of contributing factors to food insecurity and hunger $[2,6,7]$ and these problems are linked to mortality and morbidity, especially among children. Various studies have shown that sub-Saharan Africa and South Asia face this challenge due to the high proportion of people living below the international poverty line [8-11]. However, South Asia is making progress in improving income and calorie consumption [12], while African governments have been slow to take action to reduce the burden of malnutrition and promote food security in their respective countries, despite their pledge to promote food security and poverty reduction by signing the Maputo Declaration on Agriculture and Food Security in 2003 [13]. As a result, researchers describe their progress as insufficient and suboptimal [11,14]. This is of great concern as Africa's population is expected to double by 2050 [15] and population growth is a critical determinant of a country's or region's food security. Furthermore, Africa has an estimated $52 \%$ of the world's remaining arable land, but this is not evenly distributed among countries in the region [16]. Therefore, the need to assess the amount of food consumption and to use the land appropriately for sustainable food production is a step in the right direction. Nevertheless, one in three people worldwide suffers from at least one form of malnutrition [17].

Consumption of staple foods such as rice, maize and cassava is very high in low- to middle-income countries [14,18-20], while middle- to higher-income countries are consuming fewer staple foods and changing their consumption patterns towards more meat, processed foods and dairy products [14,21-23]. However, changes in dietary patterns are influenced by per capita income, lifestyle/preferences, urbanization and economic development [14,24-31], resulting in a high demand for land resources [30] to cope with the diverse food consumptions. Such changes in dietary patterns are also known to increase greenhouse gas emissions, impact the climate, contribute to unbalanced dietary intake and health-related diseases, as well as further increasing pressure on ecosystem carrying capacity and land degradation [32-38]. Besides, the total land required for food is determined by the type of food, the quantities consumed and the size of the population [39]. Available studies state that the type of food determines the land requirement for food [39] more than the quantities of food consumed per capita [40], while others assume that the land requirement for food also depends on the yield per hectare [41]. An example of this is the fact that an average Indian diet requires less land than an average diet in the United States of America, despite the size of the population [40].

Land requirements for food have been analyzed at global, regional [42,43], country and rural levels [41,44-47] using models and thought experiments such as ALBIO (Agricultural Land use and BIOmass), the Human Appropriation of Land for Food (HALF) Index, questionnaires, household food consumption surveys, data on population, dietary habits and crop yields. Their studies concluded that our food choices affect the land used for agriculture, i.e. the land required for food depends on the type of food and the rate of change in food consumption patterns. However, this interaction is causing biodiversity to decline at an accelerating rate.

Against this background, Nigeria, the most populous country in Africa, is considered as a case study. This is significant because Nigeria ranks 98 th out of 107 countries on the 2020 Global Hunger Index, has the second highest proportion of stunted children in the world [48], and an estimated 87 million people (41\%) live below the international poverty line [49]. These suggest many households in the country are undernourished, facing socioeconomic challenges and that land for food production for the teeming population may be limited. In addition, there are few studies on food consumption in Nigeria, and most focus on nutrient deficiencies, household diversity, overweight and obesity, and purchasing power $[33,50]$. Hence, there is a lack of research on food consumption in Nigeria in terms of quantity, i.e. food available per household in Nigeria by weight and land requirements for food based on their consumption pattern. Therefore, the novelty of this research is to fill the knowledge gap on food consumption patterns and LRF in Nigeria. This has prompted the study to estimate land requirements based on food consumption patterns. 
This is important as it enables effective land resource management policies and contributes significantly to the achievement of food security and sustainable production.

Our objective is therefore to analyze the temporal and spatial patterns of food consumption and the factors influencing them, and to determine the land requirements for food in the six geopolitical zones of Nigeria by combining available data on household food expenditure, selected food prices and local agricultural data. In this way, the food gap in the country and an approach to estimate how much land is currently used to feed the current population can be determined, as well as providing an outlook on the land requirements for food in the event of population growth in the future in order to initiate measures for sustainable food production.

This paper is divided as follows: The study area is presented, which gives us an overview of Nigeria. The second section deals with the methodology and datasets. The third section presents the results of our quantity analysis and land requirements for food. The fourth and fifth sections focus on the discussion and conclusion respectively. Finally, the limitations of the study are discussed.

\section{Material and Methods}

\subsection{Brief Introduction of the Study Area}

Nigeria is a multicultural country with 36 states divided into six zones based on a number of criteria, including; cultures, ethnic composition, and a common history [51] namely: North Central, North East, North West, South East, South South, and South West. Based on remotely sensed data, 8 land use land cover types were identified (see Figure 1) in the country and being an agrarian country, it has a total arable land area estimated to be about 70.8 million ha, where about 43 million ha were under cultivation, with a low incidence of irrigation farming [52]. Nigeria's climate permits the cultivation of a variety of crops and the Northern area which experiences sparse rainfall cultivates more of grains such as rice, millet, cowpeas, guinea corn, maize, and yams while the Southern areas grows more roots and tubers such as cassava, plantain, yams, and cocoyam in addition to oil palm, maize and rice [53] (see Table 1). Consequently, it has been observed that these frequently consumed traditional dietary foods are not enough to feed Nigerians [54]. Of the estimated population in 2016, the North has 54\% $(104,458,581)$ and South $46 \%(89,041,962)$. More than $70 \%$ of the Nigerian adult population is engaged in subsistence agriculture, which provides $90 \%$ of Nigeria's agricultural products, and the majority live in rural areas [55]. Nigeria is a low to a middle-income country [56], and according to a poverty index survey by the World Bank, the North has poorer households (75\%) compared to the South (25\%) [57].
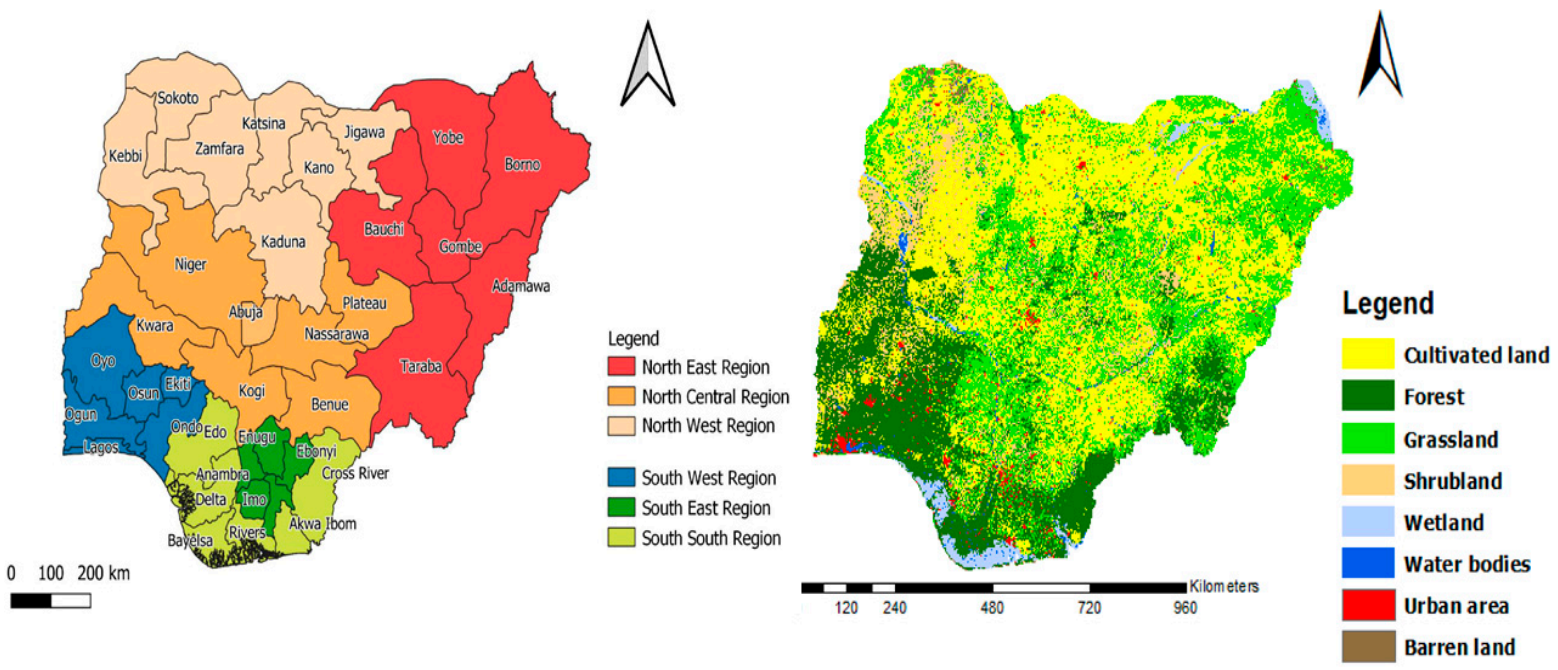

Figure 1. Location and land use land cover map of the six geopolitical zones in Nigeria. 
Table 1. The six geopolitical zones' information at a glance.

\begin{tabular}{|c|c|c|c|c|c|c|}
\hline Zones & $\begin{array}{c}\text { Average } \\
\text { Household Size } \\
(2018-2019)\end{array}$ & $\begin{array}{l}\text { Total Land Area } \\
\text { (ha) (2020) }\end{array}$ & $\begin{array}{l}\text { Cropland Area } \\
\text { (ha) (2020) }\end{array}$ & $\begin{array}{l}\text { Crops Commonly } \\
\text { Cultivated and } \\
\text { Farming System }\end{array}$ & $\begin{array}{l}\text { Population } \\
\text { (2016) }\end{array}$ & Ethnic Groups \\
\hline North Central & 5.7 & $24,242,500$ & $12,230,953$ & $\begin{array}{l}\text { Cassava, yams, } \\
\text { sorghum, millet, } \\
\text { maize, rice, cowpea, } \\
\text { and commercial } \\
\text { livestock farming. }\end{array}$ & $29,252,408$ & $\begin{array}{l}\text { Tiv, Igala, Berom, } \\
\text { and others. }\end{array}$ \\
\hline North East & 7.9 & $27,239,500$ & $11,880,402$ & $\begin{array}{c}\text { Maize, millet, } \\
\text { sorghum, wheat, rice, } \\
\text { cowpea, and } \\
\text { commercial livestock } \\
\text { farming }\end{array}$ & $26,263,866$ & Hausa \\
\hline North West & 7.4 & $21,606,500$ & $13,271,431$ & $\begin{array}{l}\text { Rice, millet, sorghum, } \\
\text { maize, cowpea, and } \\
\text { vegetables, and } \\
\text { commercial livestock } \\
\text { farming. }\end{array}$ & $48,942,307$ & Hausa \\
\hline South East & 4.3 & $2,952,500$ & $1,406,476$ & $\begin{array}{l}\text { Cassava, yams, maize } \\
\text { rice, and subsistence } \\
\text { livestock farming }\end{array}$ & $21,955,414$ & Igbo \\
\hline South South & 4.9 & $8,458,700$ & $2,507,664$ & $\begin{array}{l}\text { Cassava, yam, } \\
\text { vegetables, plantain, } \\
\text { and subsistence } \\
\text { livestock farming }\end{array}$ & $28,829,288$ & $\begin{array}{l}\text { Ibibio, Bini, Ijaw, } \\
\text { and others. }\end{array}$ \\
\hline South West & 3.2 & $7,966,500$ & $2,442,536$ & $\begin{array}{l}\text { Rice, maize, casava, } \\
\text { yam, plantain, and } \\
\text { subsistence livestock } \\
\text { farming. }\end{array}$ & $38,257,260$ & Yoruba \\
\hline National & 5.5 & $92,466,200$ & $43,739,462$ & Mixed farming & $193,500,543$ & $\begin{array}{l}\text { Major: Igbo, } \\
\text { Hausa and } \\
\text { Yoruba }\end{array}$ \\
\hline
\end{tabular}

\subsection{Data Source}

In this study, the food balance sheet and production data of the Food and Agricultural Organization from 2000 to 2018 were used [58], including the General Household Survey in Nigeria (Living Standard Measurement Survey Wave 4) 2018-2019 [59], Consumption Expenditure Pattern in Nigeria [60], and Selected Food Price list from the Nigeria National Bureau of Statistics [61]. The GHS has a national sample size of approximately 5000 participating households at both urban and rural levels. To obtain an overview of the level of food consumption in Nigeria, the FAO (FAOSTAT) data for Nigeria from 2000 to 2018 were analyzed. However, due to the inconsistency and lack of data on cowpea in the FAO data, it was removed from the analysis of the baseline data.

Data on 2017 local food production and harvested area in the various states of Nigeria's six geopolitical zones were compiled by the Federal Ministry of Agriculture and Rural Development (FMARD) [62] and the National Agricultural Extension and Research Liaison Services-an arm of the FMARD [63]. We assumed that crop production conditions and harvested areas remained the same for our analysis, as the years are not far apart.

Land use land cover $(30 \mathrm{~m})$ data from the Globeland30 project of the National Geomatics Center of China [64] were acquired to define the LULC pattern using ArcGIS 10.6 software (see Table 2). 
Table 2. Summary of the data source information.

\begin{tabular}{ccc}
\hline Data Source & Data & Year \\
\hline $\begin{array}{c}\text { Food and Agricultural Organization } \\
\text { (FAOSTAT) }\end{array}$ & $\begin{array}{c}\text { Food Balance Sheet and } \\
\text { Production }\end{array}$ & 2000-2018, 2017 \\
\hline Nigeria Bureau of Statistics & $\begin{array}{c}\text { General Household Survey in } \\
\text { Nigeria (LSMS Wave 4) }\end{array}$ & 2018-2019 \\
\hline Nigeria Bureau of Statistics & $\begin{array}{c}\text { Consumption Expenditure } \\
\text { Pattern in Nigeria }\end{array}$ & 2019 \\
\hline Nigeria Bureau of Statistics & Selected Food Prices & 2018 \\
\hline $\begin{array}{c}\text { Federal Ministry of Agriculture and } \\
\text { Rural Development (FMARD) and } \\
\text { the National Agricultural Extension } \\
\text { and Research Liaison Services } \\
\text { (NAERLS) }\end{array}$ & $\begin{array}{c}\text { Food Crop Production and } \\
\text { Harvested Area Statistics }\end{array}$ & 2017 \\
\hline National Geomatics Center of China & 30 m land use land cover images & 2020 \\
\hline
\end{tabular}

\subsection{Calculation of Household Food Consumption and Associated Land Requirement}

The food quantity consumed by households in the six geopolitical zones was estimated from their mean household food expenditure calculated from the General Household Survey and Food Prices. To obtain the specific household food expenditure on a particular food item for the various geopolitical zones, the household food expenditure as obtained from the general household survey was multiplied by the percentage share of the national food expenditure of the same food item derived from the Consumption Expenditure Pattern in Nigeria. The reason for this calculation is to be more accurate as the GHS recorded the household food expenditures as food group aggregates (i.e., grains and flours) instead of individual food item expenditures (i.e., rice). Furthermore, the GHS mean household food expenditure data were a 7-day recall period. Therefore, the household food quantity was estimated for a year. However, due to a lack of data at the household level, the food groups under consideration to ascertain its quantity consumed based on average food expenditure and food prices in the six geopolitical zones are: Rice (Oryza sativa), Maize (Zea mays) (cereals), Cassava (Manihot esculenta), Yam (Dioscorea villosa) (starchy roots, tubers), Cowpea (Vigna unguiculata) (pulses), Onions (Allium cepa), and Tomatoes (Solanum iycopersicum) (vegetables), which are considered the traditional food system in Nigeria. Methods for analyzing these data and information are presented below.

\section{(i) Measuring household food quantity consumption.}

To determine the per annum quantity of household food consumption from their mean food expenditure in the six geopolitical zones, we applied the equation below:

$\prod_{f j=1 \ldots 6 \text { geopolzone }}^{\text {Expenditure }}=\sum$ (household food expenditure $(\mathrm{f}) \times \mathrm{\%}$ share in food consumption expenditure pattern in Nigeria)

Therefore, to estimate the per annum household food quantity consumption, we used:

$$
\mathbf{Q}_{f h}=\sum\left(\frac{\prod_{f j=1 \ldots 6 \text { geopolzone }}^{\text {Expenditure }}}{\mathbf{P} f}\right) \times 365 \text { days }
$$

where:

$$
\prod_{f j=1 \ldots 6 \text { geopolzone }}^{\text {Expenditure }}=\text { food expenditure on food commodity }(f) \text { consumed by household }
$$

(j) in the six geopolitical zones in Nigeria,

$\mathbf{Q}_{f h}=$ the per annum quantity of food consumption per household in the six geopolitical zones, 
The food consumption quantity FAOSTAT food balance sheet.

The specific land requirement $\left(\mathrm{m}^{2}\right.$ year $\left.\mathrm{kg}-1\right)$ calculated by dividing consumption $(\mathrm{kg})$ by yield ( $\mathrm{kg} / \mathrm{ha})$.

The per capita land requirements $\left(\mathrm{m}^{2}\right)=$ food consumption quantity multiplied by the specific land requirements of the food crops
$\mathbf{P}_{f}=$ the price per $\mathrm{kg}$ of the individual food items $(f)$ in the six geopolitical zones in Nigeria.

Lastly, a Pearson correlation coefficient function was used to establish a relationship between household sizes and food expenditures using IBM SPSS 23.

\section{(ii) Estimating land requirements for food.}

The estimation of land requirements for food was analyzed in two parts, at the national level and in the six geopolitical zones, following a systematic approach.

Part 1: LRF at the national level.

LRF at the national level from 2000 to 2018 was estimated from major food consumption quantity (kg/capita/year) of rice, maize, cassava, yam, onions, and tomatoes from the FAOSTAT production dataset. However, due to the paucity of cowpea data from the FAO dataset, it was removed from the baseline analysis.

The steps involved in estimating LRF at the national level:

(a) The food consumption quantity ( $\mathrm{kg}$ /capita/year) of rice, maize, cassava, yam, onions, and tomatoes was calculated from the FAOSTAT food balance sheet from 2000 to 2018.

(b) The specific land requirements $\left(\mathrm{m}^{2}\right.$ year $\left.\mathrm{kg}^{-1}\right)$ for each food considered in our research were calculated by dividing consumption $(\mathrm{kg})$ in $(\mathrm{a})$ by yield $(\mathrm{kg} / \mathrm{ha})$ collated from FAOSTAT from 2000 to 2018.

(c) The per capita land requirements $\left(\mathrm{m}^{2}\right)$ for food were also calculated by combining the food consumption results in (a) and the specific land requirements of the food crops in (b) (see Figure 2).

\section{LRF at the national level from 2000-2018}

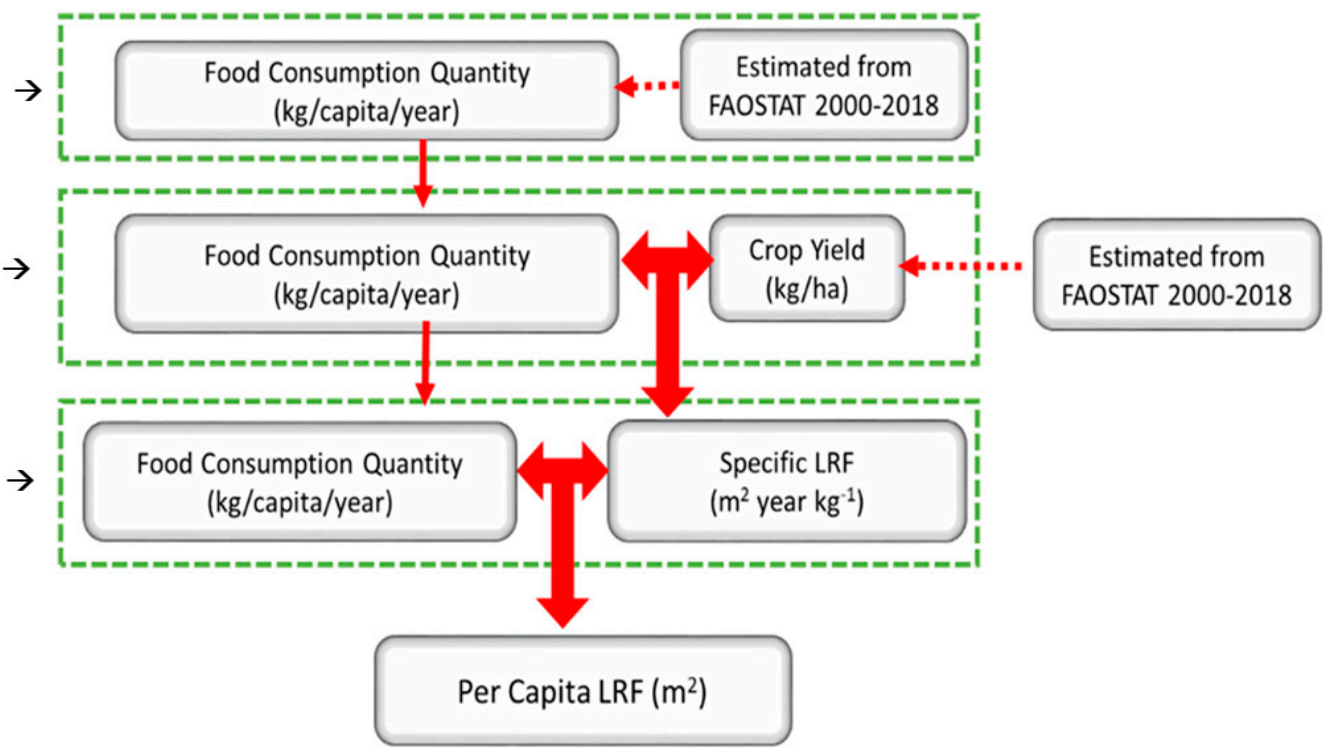

Figure 2. Diagram illustrating land requirements for food calculation at the national level.

Part 2: LRF in the six geopolitical zones.

LRF at the household level was estimated using the per annum household food quantity consumption from Equation (2) above, for rice, maize, cassava, yam, cowpea, onions, and tomatoes, and crop yield from the crop production and harvested area of 2017 in the 36 states therein grouped into the 6 geopolitical zones for the 2018-2019 analysis.

In the analysis of household LRF, yield data were not available in some states for some of the crops examined in this study. Therefore, we used the national average yield value for 2017 from the FAO crop production data as a proxy, with the assumption that the soil conditions for the yield of the proxy crop are the same in the few states for which yield data were not available. 


\section{The steps involved in estimating LRF in the six geopolitical zones:}

(a) The LRF at the household level was calculated using the household food consumption quantity ( $\mathrm{kg} /$ household/year) of rice, maize, cassava, yam, cowpea, onions, and tomatoes from Equation (2) above.

(b) To estimate the yield ( $\mathrm{kg} / \mathrm{ha}$ ) as it is needed to calculate the LRF in the six geopolitical zones, the 36 states were grouped into their respective geopolitical zones and their average crop production and harvested area of rice, maize, cassava, yam, cowpea, onions, and tomatoes were calculated.

(c) To calculate the specific land requirements for food (ha/year), the 36 states were grouped into their respective geopolitical zones and each food item consumption quantity in (a) which was derived from Equation (2) ( $\mathrm{kg} /$ household/year) was divided by their specific yield (ha) results obtained in (b).

(d) The per capita land requirements (ha) for food in the six geopolitical zones were calculated by multiplying the specific LRF (ha/year) in (c) by the food consumption quantity from Equation (2) ( $\mathrm{kg} /$ household/year).

(e) The total land requirement per household in the six geopolitical zones was calculated by multiplying the per capita land requirements (ha) in (d) by their corresponding household size; that is, North Central (5.7), North East (7.9), North West (7.4), South East (4.3), South South (4.9), and South West (3.2) (see Figure 3).

LRF at the household level 2018- 2019

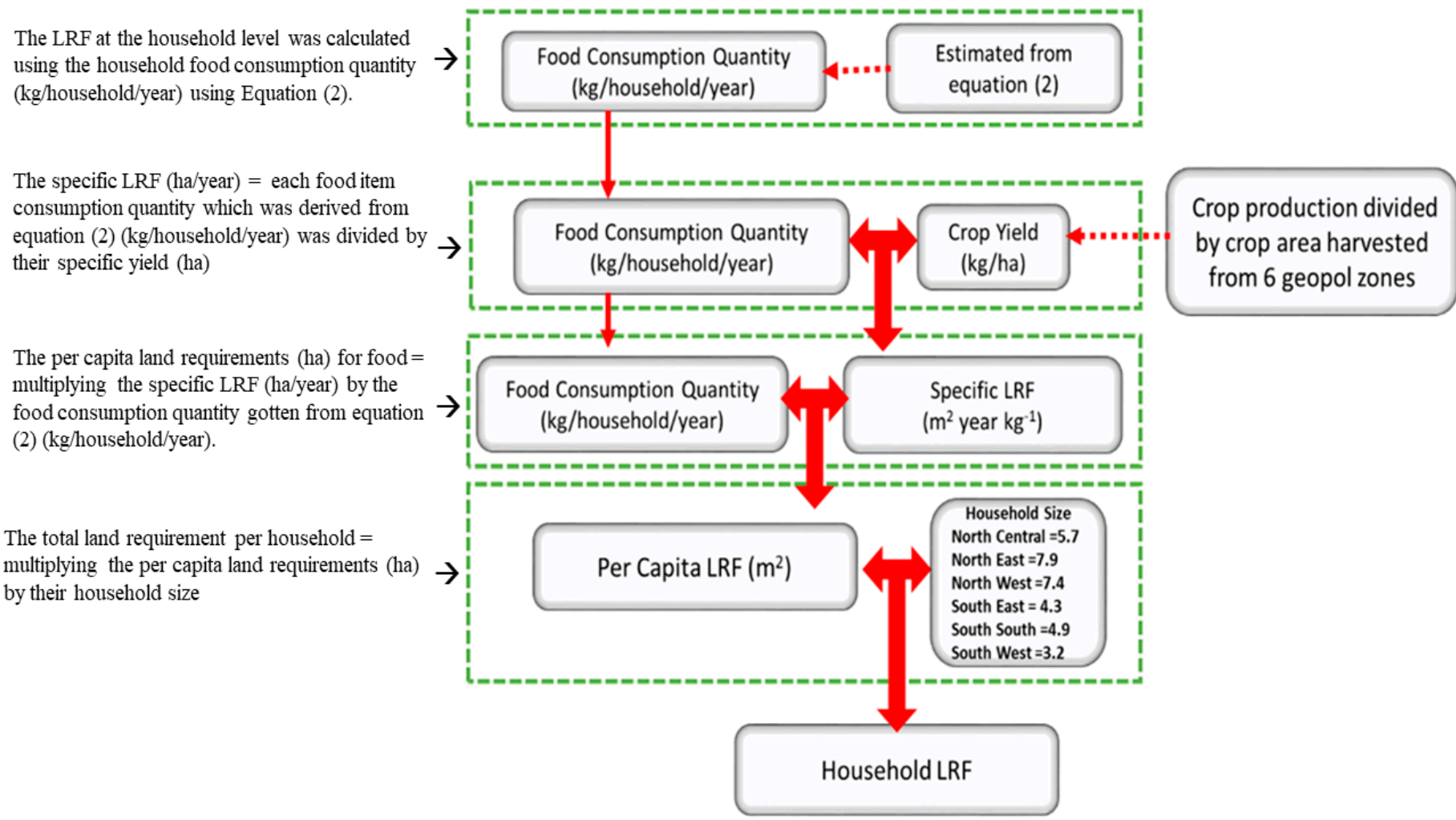

Figure 3. Diagram illustrating land requirements for food calculation in the six geopolitical zones.

\section{Results}

\subsection{Food Consumption Patterns}

3.1.1. Food Consumption Patterns at the National Level

The summary of results as calculated by the FAO food balance sheets indicated that Nigeria's total food consumption gradually increased from about $260 \mathrm{~kg} /$ capita in 2000 to $346.3 \mathrm{~kg}$ / capita in 2018, peaking in 2014. Cassava and yam dominated food consumption, followed by rice, maize, tomatoes, and onions, respectively. 
Rice, which is the most popular staple, increased from $21.96 \mathrm{~kg} /$ capita in 2000 to $39 \mathrm{~kg} /$ capita in 2018, while maize showed a significant increased from $17.71 \mathrm{~kg} / \mathrm{capita}$ in 2000 to $33.7 \mathrm{~kg}$ /capita in 2018 (see Figure 4). In as much as the cassava consumption pattern trend was significant, the consumption quantity declined from $140 \mathrm{~kg}$ in 2000 to $130.19 \mathrm{~kg}$ in 2018. Yam and tomato showed significant per capita increments (74-119 and $9.16-16.61 \mathrm{~kg} /$ capita, respectively), while onion consumption was $4.83 \mathrm{~kg} /$ capita in 2000 and $6.75 \mathrm{~kg} /$ capita in 2018 (see Figure 4).

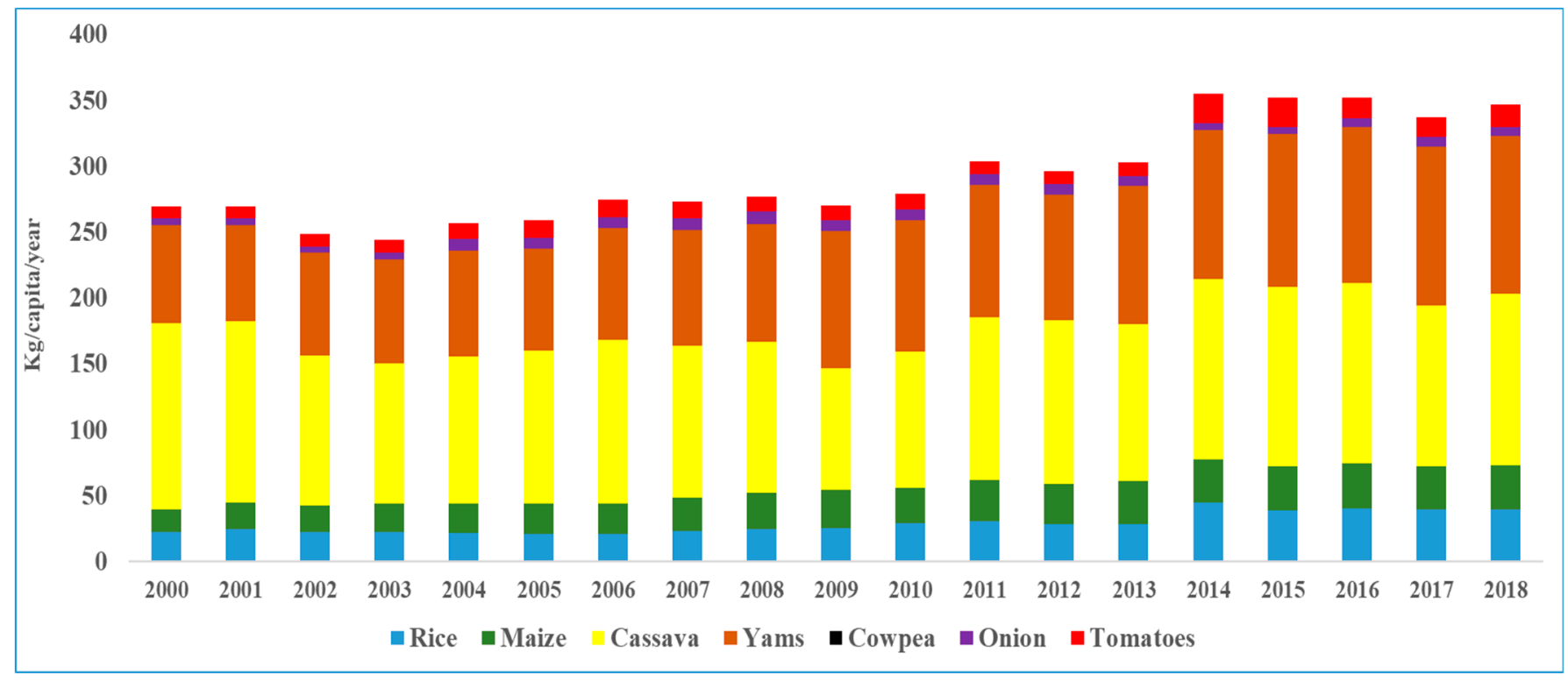

Figure 4. Nigeria food consumption pattern (kg/capita/year) from 2000 to 2018 (FAOSTAT).

\subsubsection{Food Consumption Patterns in the Six Geopolitical Zones}

Of the six geopolitical zones, the North West had the highest per capita consumption of rice $(137.81 \mathrm{~kg} /$ capita/year), followed by North East $(112.1 \mathrm{~kg} /$ capita/year) and North Central (90.05 kg/capita/year), while the South West consumed $56.71 \mathrm{~kg} / \mathrm{capita} /$ year, South East $40.84 \mathrm{~kg} /$ capita/year, and South South $31.25 \mathrm{~kg} /$ capita/year, respectively.

Similarly, per capita maize consumption is also high in the North, as the North East consumed $186.04 \mathrm{~kg}$ /capita/year, North West $139.49 \mathrm{~kg} /$ capita/year, and North Central $59.54 \mathrm{~kg} /$ capita/year. Likewise, in maize consumption, the South West remains the highest per capita consumer of maize in the South, with $31.27 \mathrm{~kg} /$ capita/year, followed by South East $8.48 \mathrm{~kg} /$ capita/year and South South $4.43 \mathrm{~kg} /$ capita/year. The high consumption of rice and maize thus shows that cereals are an important staple food for people in the North (Table 3).

Table 3. Total per annum household food quantity consumption in the six geopolitical zones.

\begin{tabular}{|c|c|c|c|c|c|c|c|c|c|}
\hline Zones & $\begin{array}{c}\text { Average } \\
\text { Household } \\
\text { Size }\end{array}$ & $\begin{array}{c}\text { Combined } \\
\text { Population } \\
\text { (2016) }\end{array}$ & $\begin{array}{l}\text { RICE } \\
(\mathbf{k g})\end{array}$ & $\begin{array}{l}\text { MAIZE } \\
\text { (kg) }\end{array}$ & $\begin{array}{c}\text { CASSAVA } \\
(\mathbf{k g})\end{array}$ & $\begin{array}{l}\text { YAM } \\
(\mathbf{k g})\end{array}$ & $\begin{array}{c}\text { COWPEA } \\
(\mathrm{kg})\end{array}$ & $\begin{array}{c}\text { ONION } \\
\text { (kg) }\end{array}$ & $\begin{array}{c}\text { TOMATO } \\
(\mathbf{k g})\end{array}$ \\
\hline North Central & 5.7 & & 513.30 & 339.37 & 507.10 & 388.93 & 85.59 & 160.66 & 146.79 \\
\hline North East & 7.9 & $104,458,581$ & 885.59 & 1469.69 & 141.22 & 179.66 & 145.06 & 225.81 & 186.61 \\
\hline North West & 7.4 & & 1019.82 & 1032.20 & 103.52 & 92.86 & 84.04 & 210.00 & 168.43 \\
\hline South East & 4.3 & & 175.61 & 36.48 & 686.55 & 683.66 & 56.28 & 222.25 & 186.56 \\
\hline South South & 4.9 & $89,041,962$ & 153.12 & 21.71 & 978.13 & 647.00 & 79.03 & 133.68 & 93.10 \\
\hline South West & 3.2 & & 181.49 & 100.07 & 209.44 & 159.52 & 39.07 & 113.48 & 99.62 \\
\hline
\end{tabular}

The per capita quantity of cassava consumption shows that households in the South South consumed more cassava (199.62 kg/capita/year), followed by South East (159.66 kg/capita/year), North Central (88.96 kg/capita/year), and South West 
(65.45 kg/capita/year), while households with low per capita consumption of cassava were in the North East (17.88 kg/capita/year) and North West (13.98 kg/capita/year).

Yam consumption was highest in the South East (158.99 kg/capita/year), South South (132.04 kg/capita/year), and North Central (68.23 kg/capita/year), while it was lower in the South West (49.85 kg/capita/year), North East (22.74 kg/capita/year), and North West (12.55 kg/capita/year).

The total quantity of cowpea consumption was higher in the North than in the South. However, by per capita consumption, the North East is the highest (18.36 kg/capita/year), closely followed by South South $(16.13 \mathrm{~kg} /$ capita/year), North Central (15.02 kg/capita/year), South East (13.09 kg/capita/year), North West (11.36 kg/capita/year), and South West (12.21 kg/capita/year).

Summarizing the quantities of staple foods consumed (excluding onions and tomatoes) by geopolitical zones in Nigeria, North East and North West had the highest total food quantity consumption of 2821.22 and $2332.44 \mathrm{~kg} /$ year, respectively, albeit mainly from cereals. Following behind are South South (1878.99 kg/year), North Central (1834.28 kg/year), South East (1638.58 kg/year), and South West (689.58 kg/year). However, by per capita consumption derived from their household sizes, South South and South East consumed more food (383.47 and $381.06 \mathrm{~kg} /$ capita/year) respectively, followed by North East (357.12 kg/capita/year), North Central (321.80 kg/capita/year), North West (315.20 kg/capita/year), and finally, South West (215.49 kg/capita/year) (see Figure 5). Therefore, the results from the food consumption quantity across the 6 geopolitical zones in Nigeria show that North Central had a $16.4 \%$ share of the total average, North East 25.2\%, North West $20.8 \%$, South East $14.6 \%$, South South $16.8 \%$, and South West $6.2 \%$.

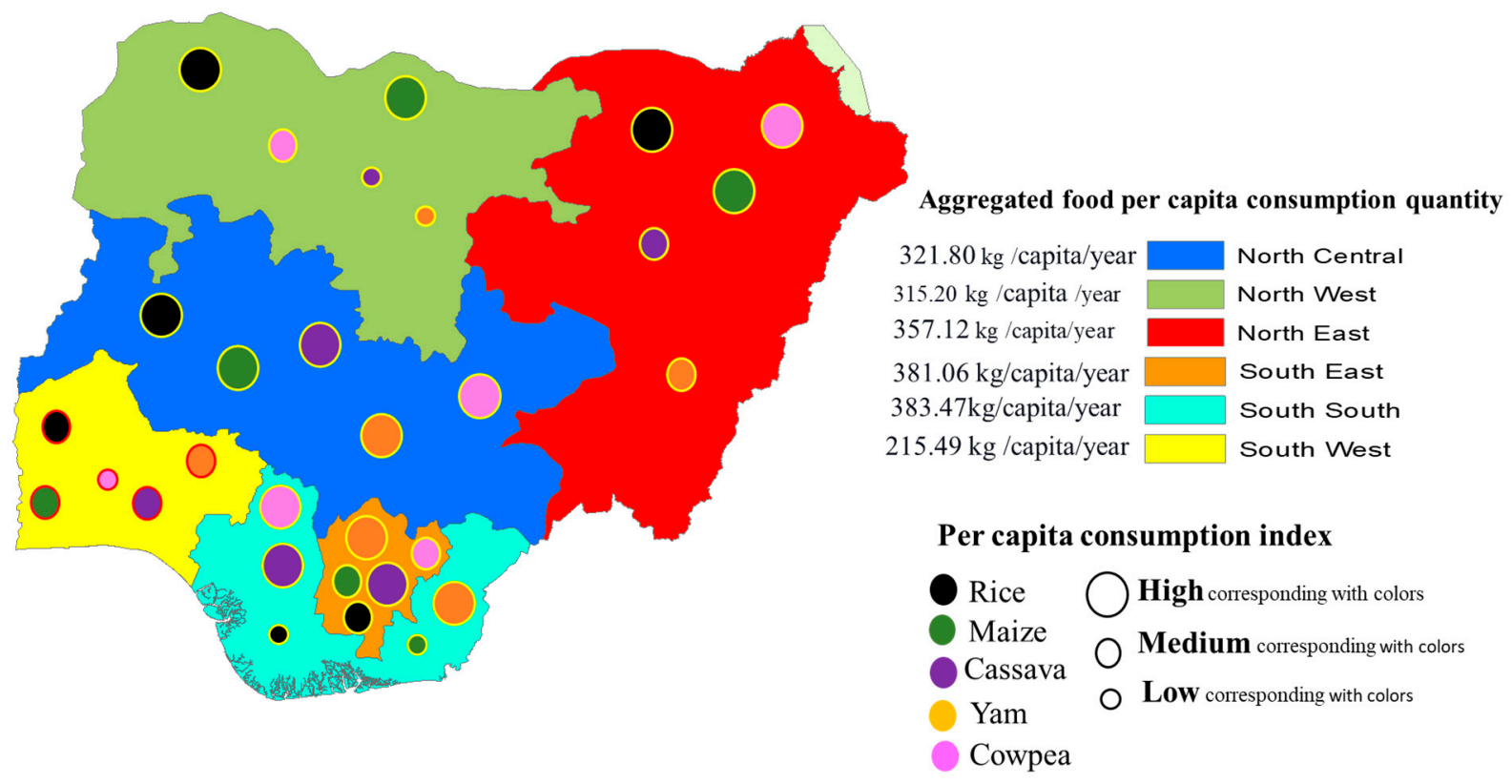

Figure 5. Pictorial representation of per annum household food consumption distribution and the rate of consumption of staple food (excluding onion and tomato) in the six geopolitical zones.

\subsection{Analysis of Land Requirements for Food}

\subsubsection{LRF at the National Level}

The per capita land required for staple food was decoupled to observe the specific land requirements for the food considered in this study. From the FAO data, it shows that the per capita land requirements percentage increase of rice and maize was $231.7 \%$ and $192.1 \%$, respectively, from 2000 to 2018. Cassava per capita LR decreased by $64.7 \%$ from 2000 to 2009 , and later increased by $180.2 \%$ from 2009 to 2018. Other food items' land requirements, 
such as yam, onions, and tomato, increased by $249.4 \%, 280 \%$, and $76.7 \%$, respectively, from 2000 to 2018.

\subsubsection{Land Requirements for Food in the Six Geopolitical Zones}

The specific and household land requirements for food varied across the six geopolitical zones (see Table 4). Rice, a popular staple in Nigeria, had a high per capita demand for land, especially in the North. Rice per capita land requirement was 10.20 ha/capita/year in North West, 8.18 ha/capita/year in North East, and 3.06 ha/capita/year in North Central, while the South West had 0.79 ha/capita/year, South East 0.53 ha/capita/year, and South South 0.38 ha/capita/year.

In addition, maize also has high per capita requirements in the North compared to the South. The North East per capita LR for maize was 19.35 ha/capita/year, North West 9.62 ha/capita/year, North Central 1.13 ha/capita/year, and their Southern counterparts have a low per capita land requirement for maize: South West 0.22 ha/capita/year, South South 0.1 ha/capita/year, and South East 0.03 ha/capita/year.

In terms of starchy roots, the household land requirements for cassava show that the food is consumed more in the South South (17.59 ha/year), South East (6.19 ha/year), and North Central (4.56 ha/year), while it has low household land requirements in the South West (0.42 ha/year), North East (0.40 ha/year), and North West ( 0.22 ha/year) due to its lower consumption rate. Similarly, the household land requirements for yam are high in the South South (7.11 ha/year) and South East (5.46 ha/year), followed by North Central (1.14 ha/year), North East (0.87 ha/year), South West (0.32 ha/year), and North West (0.30 ha/year).

Cowpea, which serves as a major source of protein in most households, has a land requirement of $2.29 \mathrm{ha}$ /year in the North East, which is the highest, followed by North Central (0.97 ha/year), South South (0.88 ha/year), North West (0.81 ha/year), South East (0.39 ha/year), and South West (0.22 ha/year).

Onion and tomato are vegetables used in daily cooking across the six geopolitical zones, and onion has higher household land requirements across the six geopolitical zones compared to tomato (see Table 4).

Lastly, the household land requirement for food in the six geopolitical zones was 515.10 ha/year. Therefore, the percentage distribution across the country shows that North Central had 7.04\%, North East 43.4\%, North West 29.15\%, South East $10.78 \%$, South South $8.23 \%$, and South West $1.4 \%$ of the total average of the household land requirements for food.

Table 4. Land requirements per food item based on food quantity consumption in the 6 geopolitical zones.

\begin{tabular}{|c|c|c|c|c|c|c|c|}
\hline Zones & Food Item & $\begin{array}{l}\text { Specific Land } \\
\text { Requirement } \\
\text { (ha/Year kg-1) }\end{array}$ & $\begin{array}{l}\text { Per Capita } \\
\text { Food } \\
\text { Consumption } \\
\text { (kg/Capita/Year) }\end{array}$ & $\begin{array}{c}\text { Total Household } \\
\text { Food } \\
\text { Consumption } \\
\left(\mathrm{kg} \mathrm{Year}^{-1}\right)\end{array}$ & $\begin{array}{c}\text { Per Capita } \\
\text { Land } \\
\text { Requirement } \\
\text { (ha/Year) }\end{array}$ & $\begin{array}{l}\text { Household } \\
\text { Land } \\
\text { Requirement } \\
\text { (ha/Year) }\end{array}$ & $\begin{array}{c}\text { Household } \\
\text { Sizes }\end{array}$ \\
\hline \multirow{8}{*}{ North Central } & Rice & 0.034 & 90.05 & 513.30 & 3.06 & 17.44 & \multirow{7}{*}{5.7} \\
\hline & Maize & 0.019 & 59.54 & 339.37 & 1.13 & 6.44 & \\
\hline & Cassava & 0.009 & 88.96 & 507.10 & 0.80 & 4.56 & \\
\hline & Yam & 0.003 & 68.23 & 388.93 & 0.20 & 1.14 & \\
\hline & Cowpea & 0.011 & 15.02 & 85.59 & 0.17 & 0.97 & \\
\hline & Onion & 0.032 & 28.19 & 160.66 & 0.90 & 5.13 & \\
\hline & Tomato & 0.004 & 25.75 & 146.79 & 0.10 & 0.57 & \\
\hline & Sub-total & 0.112 & 375.74 & 2141.74 & 6.37 & 36.25 & \\
\hline \multirow{8}{*}{ North East } & Rice & 0.073 & 112.10 & 885.59 & 8.18 & 64.62 & \multirow{7}{*}{7.9} \\
\hline & Maize & 0.104 & 186.04 & 1469.69 & 19.35 & 152.87 & \\
\hline & Cassava & 0.003 & 17.88 & 141.22 & 0.05 & 0.40 & \\
\hline & Yam & 0.005 & 22.74 & 179.66 & 0.11 & 0.87 & \\
\hline & Cowpea & 0.016 & 18.36 & 145.06 & 0.29 & 2.29 & \\
\hline & Onion & 0.008 & 28.58 & 225.81 & 0.23 & 1.82 & \\
\hline & Tomato & 0.004 & 23.62 & 186.61 & 0.09 & 0.71 & \\
\hline & Sub-total & 0.213 & 409.32 & 3233.64 & 28.32 & 223.57 & \\
\hline
\end{tabular}


Table 4. cont.

\begin{tabular}{|c|c|c|c|c|c|c|c|}
\hline Zones & Food Item & $\begin{array}{l}\text { Specific Land } \\
\text { Requirement } \\
\left(\text { ha/Year kg } \text { kg) }^{-1}\right.\end{array}$ & $\begin{array}{l}\text { Per Capita } \\
\text { Food } \\
\text { Consumption } \\
\text { (kg/Capita/Year) }\end{array}$ & $\begin{array}{l}\text { Total Household } \\
\text { Food } \\
\text { Consumption } \\
\left.\text { (kg Year }{ }^{-1}\right)\end{array}$ & $\begin{array}{l}\text { Per Capita } \\
\text { Land } \\
\text { Requirement } \\
\text { (ha/Year) }\end{array}$ & $\begin{array}{l}\text { Household } \\
\text { Land } \\
\text { Requirement } \\
\text { (ha/Year) }\end{array}$ & $\begin{array}{c}\text { Household } \\
\text { Sizes }\end{array}$ \\
\hline \multirow{8}{*}{ North West } & Rice & 0.074 & 137.81 & 1019.82 & 10.20 & 75.48 & \multirow{7}{*}{7.4} \\
\hline & Maize & 0.069 & 139.49 & 1032.20 & 9.62 & 71.19 & \\
\hline & Cassava & 0.002 & 13.99 & 103.52 & 0.03 & 0.22 & \\
\hline & Yam & 0.003 & 12.55 & 92.86 & 0.04 & 0.30 & \\
\hline & Cowpea & 0.010 & 11.36 & 84.04 & 0.11 & 0.81 & \\
\hline & Onion & 0.007 & 28.38 & 210.00 & 0.20 & 1.48 & \\
\hline & Tomato & 0.004 & 22.76 & 168.43 & 0.09 & 0.67 & \\
\hline & Sub-total & 0.169 & 366.34 & 2710.87 & 20.29 & 150.15 & \\
\hline \multirow{8}{*}{ South East } & Rice & 0.013 & 40.84 & 175.61 & 0.53 & 2.28 & \multirow{7}{*}{4.3} \\
\hline & Maize & 0.003 & 8.48 & 36.48 & 0.03 & 0.13 & \\
\hline & Cassava & 0.009 & 159.66 & 686.55 & 1.44 & 6.19 & \\
\hline & Yam & 0.008 & 158.99 & 683.66 & 1.27 & 5.46 & \\
\hline & Cowpea & 0.007 & 13.09 & 56.28 & 0.09 & 0.39 & \\
\hline & Onion & 0.179 & 51.69 & 222.25 & 9.25 & 39.78 & \\
\hline & Tomato & 0.007 & 43.39 & 186.56 & 0.30 & 1.29 & \\
\hline & Sub-total & 0.226 & 476.14 & 2047.39 & 12.91 & 55.51 & \\
\hline \multirow{8}{*}{ South South } & Rice & 0.012 & 31.25 & 153.12 & 0.38 & 1.86 & \multirow{7}{*}{4.9} \\
\hline & Maize & 0.002 & 4.43 & 21.71 & 0.01 & 0.05 & \\
\hline & Cassava & 0.018 & 199.62 & 978.13 & 3.59 & 17.59 & \\
\hline & Yam & 0.011 & 132.04 & 647.00 & 1.45 & 7.11 & \\
\hline & Cowpea & 0.011 & 16.13 & 79.03 & 0.18 & 0.88 & \\
\hline & Onion & 0.108 & 27.28 & 133.68 & 2.95 & 14.46 & \\
\hline & Tomato & 0.005 & 19.00 & 93.10 & 0.09 & 0.44 & \\
\hline & Sub-total & 0.167 & 429.75 & 2105.77 & 8.65 & 42.39 & \\
\hline \multirow{9}{*}{ South West } & Rice & 0.014 & 56.71 & 181.49 & 0.79 & 2.53 & \multirow{7}{*}{3.2} \\
\hline & Maize & 0.007 & 31.27 & 100.07 & 0.22 & 0.70 & \\
\hline & Cassava & 0.003 & 65.45 & 209.44 & 0.13 & 0.42 & \\
\hline & Yam & 0.002 & 49.85 & 159.52 & 0.10 & 0.32 & \\
\hline & Cowpea & 0.006 & 12.21 & 39.07 & 0.07 & 0.22 & \\
\hline & Onion & 0.025 & 35.46 & 113.48 & 0.89 & 2.85 & \\
\hline & Tomato & 0.002 & 31.13 & 99.62 & 0.06 & 0.19 & \\
\hline & Sub-total & 0.059 & 429.75 & 902.69 & 8.65 & 42.39 & \\
\hline & TOTAL & 0.946 & 2487.04 & $13,142.1$ & 85.19 & 515.1 & \\
\hline
\end{tabular}

\section{Discussion}

Food consumption patterns in the six geopolitical zones show that cereals and starchy roots contribute significantly (over $70 \%$ ) to household calorie requirements. Available studies have shown that developing countries rely on starchy staple foods to meet their energy needs. For example, a similar observation was made in the city of Guyuan in Northwest China that the energy needs of the population are met by staple foods [44].

The quantity of household food consumption was estimated from household food expenditure and food prices. Therefore, the share of total household expenditure (as a proxy of income) spent on food is an indicator of household food security, and low-income households spend more of their income on providing food [65]. The Nigeria National Bureau of Statistics revealed that 59.19\% was the total expenditure on food in 2019 by households in Nigeria [66]. This shows that many Nigerian households spend a substantial amount of their income on providing food, and according to experts' measurements of food security at the household level [67], this classifies households in our study as being moderately food-insecure. Based on the aforementioned findings, the North East are more food insecure as they spent more to feed themselves having the highest percentage $(25.2 \%)$ of the total average of food consumed in the six geopolitical zones, followed by the North West $(20.8 \%)$, South South (16.8\%), North Central (16.4\%), South East (14.6\%), and the least is the South West $(6.2 \%)$. 
The food consumption pattern results indicate that households are changing their dietary patterns due to their high food expenditures. This is observed in the North East and North West, indicating that the two zones are shifting their consumption patterns from rice to maize as a cheaper alternative, likewise in the South East and South South, consuming more dense calories from cassava and yam than rice and maize. Additionally, an interesting observation is that the South West consumes more cereals, especially rice, than its southern counterparts. A plausible reason for this is that the South West have more rice-producing states [68], which may have influenced the price of rice to be relatively cheaper than in other parts of the country. The North Central zones also consume more amount of cereals and starchy roots as they have the latitude to produce these crops [69].

Cowpea is one of the least consumed staple foods in terms of quantity in the six geopolitical zones, which suggests that most households prefer to consume other sources of protein, such as meat, fish, and eggs. However, cowpea serves as a good source of protein in both the North and the South. Aside direct consumption, cowpea are also used for cooking, as it can be used as a thickener [20], and popular local snacks (akara and moi-moi) are made from its derivatives.

Onions and tomatoes are among the daily cooking ingredients throughout the country, and their consumption depends on the season.

One of the factors considered in our study that influences food consumption patterns is the different household sizes. The North has an average household size of 7, and the average for the South is 4 , which further influences the quantity of food per household. To demonstrate the influence of household size on the amount of food consumed, we calculated the Pearson correlation coefficient, which showed a significant relationship of 0.636 between household size and food expenditure.

Another reason can be attributed to socio-economic aspects, such as low income and rising food prices that make it difficult to access food (see Figure A1). These factors affect the food demand and consumption pattern [70,71] as low income households tend to consume local-specific, affordable, and carbohydrate-rich food items.

Apart from land holdings and suitability for crop cultivation, food culture also has a significant impact on food choices in the country and it may be difficult for households to change their consumption patterns [69]. For brevity, a culture of making a gelatinized semi-solid paste from these grains and tubers, which are consumed with locally prepared soups by households across the country, is widespread $[20,55]$, and this is consumed more than once a day. This influence of food culture is also documented in various studies in China $[38,72]$.

In terms of land required for food, the country's specific land requirement for food has increased from 2000 to 2018 (Figure 6). This indicates that food demand and consumption is increasing for Africa's largest population. Similar observations were made in a study in the Philippines on the increasing population raising land requirements for food [46]. The Northern zones having a larger household size and population translated to higher land requirements for the food quantity they consumed compared to the Southern zones.

Rice, which is a popular staple in Nigeria, has one of the highest specific land requirements in the six geopolitical zones (Table 4). Likewise, in the Philippines in South Asia, rice was a major contributor to their land requirements for food [46]. Cereals and starchy roots are commonly consumed food groups in Nigeria, and therefore require more land based on their consumption. The North East and North West have the highest per capita land requirements for maize, which suggests that households in these zones are replacing rice consumption with maize, possibly to reduce the cost of food expenditure, as previously mentioned.

Overall, the increases in land requirements from the study are attributed to food culture, income/expenditure, and population growth. In addition, two critical findings on the land requirements for food from the study showed that the actual cropland area of the South South zone (comprising of six states) was used to feed approximately 5000 households (study sample size), and more land, which exceeded the actual total land area of Nigeria, 
will be needed to feed approximately 40 million households (see Tables 1 and 5). Therefore, considering a "business as usual" scenario on land requirements for food from our study, a further increase in population will pose a challenge to the actual arable land and its resources to accommodate the food consumption patterns.
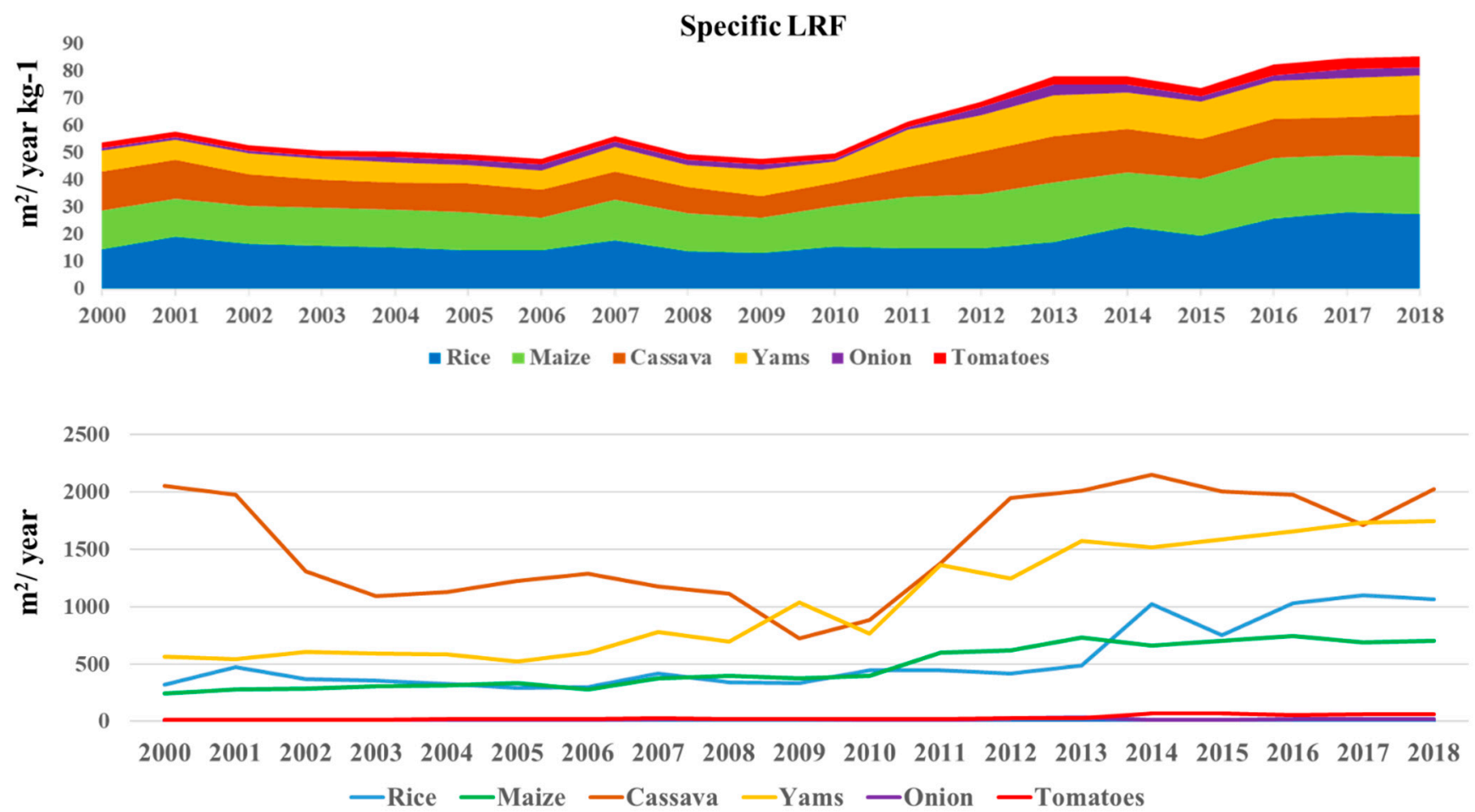

National per capita LRF

Figure 6. National specific and per capita land requirements for food in Nigeria (data source: FAOSTAT).

Table 5. Current gap in household land requirements for food in Nigeria and in the six geopolitical zones.

\begin{tabular}{|c|c|c|}
\hline Zones & $\begin{array}{c}\text { Combined Household Land Requirements } \\
\text { of the } 7 \text { Food Crops (Ha) }\end{array}$ & $\begin{array}{l}\text { Projected Household Land Requirements of the } \\
7 \text { Food Crops (Ha) }\end{array}$ \\
\hline North Central & 36.25 & \multirow{2}{*}{$\begin{array}{c}2016 \text { estimated population }=193 \text { million } \\
\downarrow\end{array}$} \\
\hline North East & 223.57 & \\
\hline North West & 150.15 & National average household size of 5 \\
\hline South East & 55.51 & \multirow{4}{*}{$\begin{array}{c}\text { Which gives } 38.6 \text { million households in Nigeria. } \\
\downarrow \\
\begin{array}{c}\text { 38.6 million households } \times \text { our study household LR } \\
\text { of } 515.1 \text { ha }\end{array}\end{array}$} \\
\hline South South & 42.39 & \\
\hline South West & 7.23 & \\
\hline TOTAL & 515.1 & \\
\hline $\begin{array}{l}\text { National } \\
\text { GHS of } 5000 \text { households }\end{array}$ & $2,575,500$ & Gap $=19,882,860,000$ \\
\hline
\end{tabular}

\section{Conclusions}

The objective of this study was to analyze the food consumption patterns over time and space to identify their influencing factors and to determine the land requirements for food in the six geopolitical zones of Nigeria. From this, the following conclusions were drawn:

(i) From the food considered in our study, households depend on rice, maize, cassava, and yams for their daily calorie requirements. This dietary pattern, which comprises of excess consumption of starchy foods, may have health and nutritional consequences. In addition, cowpea is the least consumed, albeit serving as a major source of protein 
in the country, consumed more by the Northern households than the Southern households. The South South, South East, and North Central regions consume more starchy roots, and the South West maintained the least food quantity consumed.

(ii) The household food consumption quantity was derived from household food expenditure and its corresponding food prices. Therefore, the current consumption pattern indicates that larger households will be vulnerable to food price inflation and accessibility, which poses a risk to their food security and vulnerable to undernourishment, as their food expenditure, which is high in this study, will be higher if current conditions persist.

(iii) Many households are changing their food consumption patterns to cheaper alternatives, especially from rice to maize, and rice to cassava and yam, which suggests that rice is more expensive than other food items.

(iv) Cereals and starchy roots have high household land requirements, as they are commonly consumed food groups, and the North East $(50.4 \%)$ and North West $(31 \%)$ have the highest household land requirements for food, with the South West $(0.7 \%)$ having the lowest. The driving factors include population, household sizes, income/expenditure, food culture/preference, and food prices.

(v) Food items constantly consumed by households have high land requirements across the six geopolitical zones, as seen for rice, maize, cassava, and yam, to satisfy their consumption patterns (see Table 4), irrespective of having low specific land requirements.

Finally, looking at the land requirements for food, a further increase in population without adequate food production output in the country, poses a challenge to the actual arable land and its resources to meet food consumption.

We recommend improving the standard of living of the people so that they have access to enough food for a healthy life, and making efforts to promote food diversity and improve food production to reduce the high cost of food expenditure. If expansion of cropland is considered, abandoned land can be converted to cropland and rapid urbanization and infrastructure development should take into account the need to preserve arable land for the growing population, because a future increase in the number of households without adequate food production and within the currently available cropland poses a serious challenge to food security in Nigeria.

\section{Limitations}

The use of secondary data has its limitations. In the general household survey, households may overestimate or underestimate their food expenditure. In addition, the GHS recorded the cumulative expenditure on food rather than on a single food item. We had to use the percentage share of food expenditure for each item to obtain our values. This is because the GHS did not provide information on the percentage distribution of the household sample size of 5000 and the age of household members in each geopolitical zone.

Due to the lack of recent data, the 2017 crop production and harvested area were used to estimate yield. However, for some crops, data were not available, and the national average was used. In addition, the FAO dataset contains estimated values and an inconsistent cowpea values at the national level that may have influenced the results.

The impact of the COVID-19 pandemic disrupted our preparations to travel to Nigeria for fieldwork and to obtain information on the field. Access to up-to-date national data was also a challenge. We therefore used secondary data from international organizations, Nigeria national bureau of statistics and Nigerian ministry in charge of agricultural data for this study.

Further studies are needed to include more food items to estimate their consumption quantities, determine their land requirements and propose sustainable food production techniques amidst present environmental boundaries. 
Author Contributions: Conceptualization, J.C.C. and L.Z.; methodology, J.C.C.; software, J.C.C.; validation, J.C.C., L.Z. and Y.X.; formal analysis, J.C.C.; investigation, J.C.C.; resources, L.Z.; data curation, J.C.C.; writing-original draft preparation J.C.C.; writing-review and editing J.C.C., L.Z. and Y.X.; visualization, J.C.C., L.Z. and Y.X.; supervision, L.Z.; project administration, L.Z.; funding acquisition, L.Z.. All authors have read and agreed to the published version of the manuscript.

Funding: This research received funding and support from the Strategic Priority Research Program of the Chinese Academy of Sciences (XDA20010202), the National Key Research and Development Program of China (2016YFC0503700), and the Chinese Scholarship Council (CSC).

Institutional Review Board Statement: Not applicable.

Informed Consent Statement: Not applicable.

Data Availability Statement: Food Balance Sheet and Production https:/ / www.fao.org/faostat/ en/\#data/FBS (accessed on 15 June 2020); General Household Survey in Nigeria (LSMS Wave 4) 2018-2019 https:/ / www.nigerianstat.gov.ng/ (accessed on 25 June 2020); Consumption Expenditure Pattern in Nigeria 2019 https:/ / nigerianstat.gov.ng (accessed on 8 June 2020); Selected Food Prices 2018 https:/ / nigerianstat.gov.ng/ (accessed on 25 June 2020); Food Crop Production and Harvested Area Statistics 2017 https: / / fmard.gov.ng/ (accessed on 29 June 2021); 30 m land use land cover images 2020 http:/ / www.globallandcover.com/ (accessed on 8 June 2020).

Acknowledgments: The authors also want to thank the Nigeria Federal Ministry of Agriculture and Rural Development (FMARD), National Agricultural Extension and Research Liaison Services Nigeria (NAERLS), and the anonymous reviewers for their valuable comments on the manuscript.

Conflicts of Interest: The authors declare no conflict of interest.

\section{Appendix A}

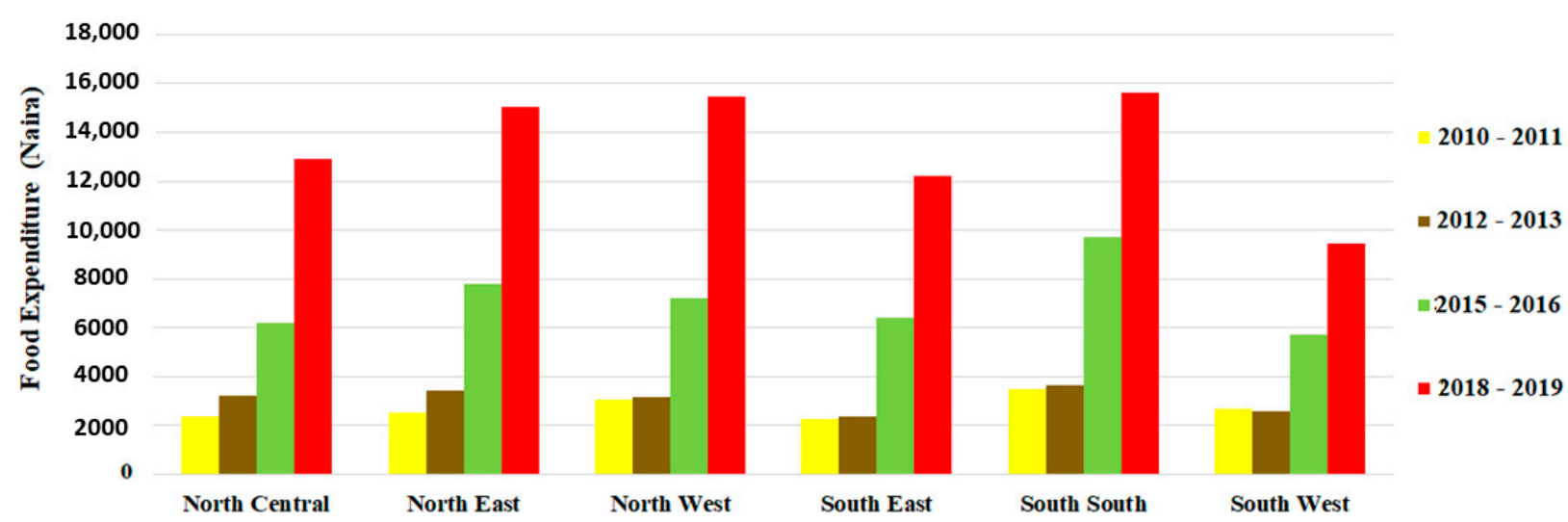

Figure A1. Food expenditure per week for grains and flours, starchy roots, tubers and plantains, pulses, nuts, and seeds, vegetables, meat, fish, and animal products for the 6 geopolitical zones from 2010 to 2019.

\section{References}

1. SDG. “2030 Agenda for Sustainable Development”—United Nations Sustainable Development Goals. 2015. Available online: https:/ / www.un.org/sustainabledevelopment/development-agenda/ (accessed on 11 December 2021).

2. Schmidt-Traub, G.; Kroll, C.; Teksoz, K.; Durand-Delacre, D.; Sachs, J.D. National baselines for the Sustainable Development Goals assessed in the SDG Index and Dashboards. Nat. Geosci. 2017, 10, 547-555. [CrossRef]

3. Osendarp, S.; Akuoku, J.K.; Black, R.E.; Headey, D.; Ruel, M.; Scott, N.; Shekar, M.; Walker, N.; Flory, A.; Haddad, L.; et al. The COVID-19 crisis will exacerbate maternal and child undernutrition and child mortality in low- and middle-income countries. Nat. Food 2021, 2, 476-484. [CrossRef]

4. Hasegawa, T.; Fujimori, S.; Takahashi, K.; Masui, T. Scenarios for the risk of hunger in the twenty-first century using Shared Socioeconomic Pathways. Environ. Res. Lett. 2015, 10, 014010. [CrossRef]

5. GNR. Global Nutrition Report: Action on Equity to End Malnutrition (Development Initiatives, 2020). 2020. Available online: https://globalnutritionreport.org/reports/2020-global-nutrition-report/ (accessed on 11 December 2021). 
6. Trollman, H.; Jagtap, S.; Garcia-Garcia, G.; Harastani, R.; Colwill, J.; Trollman, F. COVID-19 demand-induced scarcity effects on nutrition and environment: Investigating mitigation strategies for eggs and wheat flour in the United Kingdom. Sustain. Prod. Consum. 2021, 27, 1255-1272. [CrossRef] [PubMed]

7. Arumugam, S.; Özkan, B.; Jayaraman, A.; Mocka1samy, P. Impacts of COVID-19 Pandemic on Global Agriculture, Livelihoods and Food Systems. J. Agric. Sci. 2021, 27, 239-246.

8. Qaim, M. Food consumption patterns in developing countries. In Encyclopedia of Food Security and Sustainability; Elsevier Science \& Technology: Waltham, MA, USA, 2019; Volume 2.

9. Rasul, G. A Framework for Addressing the Twin Challenges of COVID-19 and Climate Change for Sustainable Agriculture and Food Security in South Asia. Front. Sustain. Food Syst. 2021, 5, 679037. [CrossRef]

10. Islam, T.T.; Newhouse, D.; Yanez-Pagans, M. International comparisons of poverty in South Asia. Asian Dev. Rev. 2021, 38, 142-175. [CrossRef]

11. Gödecke, T.; Stein, A.J.; Qaim, M. The global burden of chronic and hidden hunger: Trends and determinants. Glob. Food Secur. 2018, 17, 21-29. [CrossRef]

12. IFPRI. Global Nutrition Report; International Food Policy Research Institute: Washington, DC, USA, 2017.

13. Africa Union. In Proceedings of the Maputo Declaration on Agriculture and Food Security, Assembly of the African Union, Maputo, Mozambique, 10-12 July 2003.

14. Kearney, J. Food consumption trends and drivers. Philos. Trans. R. Soc. Lond. B Biol. Sci. 2010, 365, 2793-2807. [CrossRef] [PubMed]

15. Owoo, N.S. Demographic considerations and food security in Nigeria. J. Soc. Econ. Dev. 2021, 23, 128-167. [CrossRef]

16. Jayne, T.S.; Chamberlin, J.; Headey, D.D. Land pressures, the evolution of farming systems, and development strategies in Africa: A synthesis. Food Policy 2014, 48, 1-17. [CrossRef]

17. Baca, A.S. The Food Consumption Pattern of the Free Market: The Mexican Experience under NAFTA. Agrar. South J. Political Econ. 2019, 8, 258-286.

18. Muyanga, M.; Jayne, T.; Kodhek, G.; Ariga, J. Staple Food Consumption Patterns in Urban Kenya: Trends and Policy Implications; Tegemeo Institute of Agricultural Policy and Development, Egerton University: Nairobi, Kenya, 2005.

19. Chauvin, N.D.; Mulangu, F.; Porto, G. Food Production and Consumption Trends in Sub-Saharan Africa: Prospects for the Transformation of the Agricultural Sector; UNDP Regional Bureau for Africa: New York, NY, USA, 2012; Volume 2, p. 74.

20. Ene-Obong, H.N.; Sanusi, R.A.; Udenta, E.A.; Williams, I.O.; Anigo, K.M.; Chibuzo, E.C.; Aliyu, H.M.; Ekpe, O.O.; Davidson, G.I Data collection and assessment of commonly consumed foods and recipes in six geo-political zones in Nigeria: Important for the development of a National Food Composition Database and Dietary Assessment. Food Chem. 2013, 140, 539-546. [PubMed]

21. Savige, G.S.; Crawford, D.; Worsley, A.; Ball, K. Food intake patterns among Australian adolescents. Asia Pac. J. Clin. Nutr. 2007, 16, 738-747. [PubMed]

22. Rivera, J.Á.; De Cossío, T.G.; Pedraza, L.S.; Aburto, T.C.; Sánchez, T.G.; Martorell, R. Childhood and adolescent overweight and obesity in Latin America: A systematic review. Lancet Diabetes Endocrinol. 2014, 2, 321-332. [CrossRef]

23. Partearroyo, T.; Samaniego-Vaesken, M.D.L.; Ruiz, E.; Aranceta-Bartrina, J.; Gil, Á.; González-Gross, M.; Ortega, R.M.; SerraMajem, L.; Varela-Moreiras, G. Current food consumption amongst the spanish anibes study population. Nutrients 2019, 11, 2663. [CrossRef]

24. Cao, L.J.; Tian, W.-M.; Wang, J.-M.; Malcolm, B.; Liu, H.-B.; Zhou, Z.-Y. Recent Food Consumption Trends in China and Trade. Australas. Agribus. Rev. 2013, 21, 15-44.

25. Akram, W.; Henneberry, S. Consumption Patterns of Urban Punjab of Pakistan: Evidence from HIES 2013-2014. In Proceedings of the Agricultural \& Applied Economics Association Annual Meeting, Boston, MA, USA, 31 July-2 August 2016.

26. Galbete, C.; Nicolaou, M.; Meeks, K.A.; De Graft-Aikins, A.; Addo, J.; Amoah, S.K.; Smeeth, L.; Owusu-Dabo, E.; KlipsteinGrobusch, K.; Bahendeka, S.; et al. Food consumption, nutrient intake, and dietary patterns in Ghanaian migrants in Europe and their compatriots in Ghana. Food Nutr. Res. 2017, 61, 1341809. [CrossRef]

27. Streeter, J.L. Socioeconomic factors affecting food consumption and nutrition in China: Empirical evidence during the 1989-2009 period. Chin. Econ. 2017, 50, 168-192. [CrossRef]

28. Song, F.; Cho, M.S. Geography of food consumption patterns between South and North China. Foods 2017, 6, 34. [CrossRef]

29. Mottaleb, K.A.; Rahut, D.B.; Kruseman, G.; Erenstein, O. Changing food consumption of households in developing countries: A Bangladesh case. J. Int. Food Agribus. Mark. 2018, 30, 156-174. [CrossRef]

30. Sharma, R.; Nguyen, T.T.; Grote, U. Changing consumption patterns-Drivers and the environmental impact. Sustainability 2018, 10, 4190. [CrossRef]

31. Saleem, S.B.; Ali, Y. Effect of lifestyle changes and consumption patterns on environmental impact: A comparison study of Pakistan and China. Chin. J. Popul. Resour. Environ. 2019, 17, 113-122. [CrossRef]

32. Razack, N.; Ludin, A. Ecological footprint and food consumption in Minna, Nigeria. In IOP Conference Series: Earth and Environmental Science; IOP Publishing: Bristol, UK, 2014.

33. Akerele, D. Household food expenditure patterns, food nutrient consumption and nutritional vulnerability in Nigeria: Implications for policy. J. Ecol. Food Nutr. 2015, 54, 546-571. [CrossRef]

34. Ranganathan, J.; Vennard, D.; Waite, R.; Searchinger, T.; Dumas, P.; Lipinski, B. Shifting diets: Toward a sustainable food future. In Global Food Policy Report; International Food Policy Research Institute (IFPRI): Washington, DC, USA, 2016. 
35. Ray, S.; Bhattacharyya, B. A statistical investigation on analysis of food consumption pattern in India. J. Crop Weed 2016, 12, 47-54.

36. Zhen, L.; Du, B. Ecological Footprint Analysis Based on Changing Food Consumption in a Poorly Developed Area of China. Sustainability 2017, 9, 1323. [CrossRef]

37. Ecker, O. Agricultural transformation and food and nutrition security in Ghana: Does farm production diversity (still) matter for household dietary diversity? Food Policy 2018, 79, 271-282. [CrossRef]

38. Yin, J.; Yang, D.; Zhang, X.; Zhang, Y.; Cai, T.; Hao, Y.; Cui, S.; Chen, Y. Diet shift: Considering environment, health and food culture. Sci. Total Environ. 2020, 719, 137484. [CrossRef] [PubMed]

39. Gerbens-Leenes, W.; Nonhebel, S. Food and land use. The influence of consumption patterns on the use of agricultural resources Appetite 2005, 45, 24-31. [CrossRef]

40. Alexander, P.; Brown, C.; Arneth, A.; Finnigan, J.; Rounsevell, M.D.A. Human appropriation of land for food: The role of diet. Glob. Environ. Chang. 2016, 41, 88-98. [CrossRef]

41. Gerbens-Leenes, P.W.; Nonhebel, S.; Ivens, W.P.M.F. A method to determine land requirements relating to food consumption patterns. Agric. Ecosyst. Environ. 2002, 90, 47-58. [CrossRef]

42. Wirsenius, S.; Azar, C.; Berndes, G. How much land is needed for global food production under scenarios of dietary changes and livestock productivity increases in 2030? Agric. Syst. 2010, 103, 621-638. [CrossRef]

43. Kastner, T.; Rivas, M.J.I.; Koch, W.; Nonhebel, S. Global changes in diets and the consequences for land requirements for food Proc. Natl. Acad. Sci. USA 2012, 109, 6868-6872. [CrossRef] [PubMed]

44. Zhen, L.; Cao, S.; Cheng, S.; Xie, G.; Wei, Y.; Liu, X.; Li, F. Arable land requirements based on food consumption patterns: Case study in rural Guyuan District, Western China. Ecol. Econ. 2010, 69, 1443-1453. [CrossRef]

45. Das, K.; Nonhebel, S. A comparative study of the land required for food and cooking fuel in rural India. Agric. Syst. 2019, 176, 102682. [CrossRef]

46. Kastner, T.; Nonhebel, S. Changes in land requirements for food in the Philippines: A historical analysis. Land Use Policy 2010, 27, 853-863. [CrossRef]

47. Hoff, M.; De Boer, H.J. A Question-Based Method to Calculate the Human Appropriation of Land for Food (HALF) Index Sustainability 2020, 12, 10597. [CrossRef]

48. UNICEF. Nutrition Report on Nigeria; United Nations International Children's Emergency Fund: New York, NY, USA, 2019.

49. WorldPoverty. World Poverty Clock; World Data: Vienna, Austria, 2020.

50. Mekonnen, D.A.; Trijsburg, L.; Achterbosch, T.; Brouwer, I.D.; Kennedy, G.; Linderhof, V.; Ruben, R.; Talsma, E.F. Food consumption patterns, nutrient adequacy, and the food systems in Nigeria. Agric. Food Econ. 2021, 9, 16. [CrossRef]

51. Ajakaiye, O.; Jerome, A.T.; Olaniyan, O.; Mahrt, K.; Alaba, O.A. Spatial and temporal multidimensional poverty in Nigeria. In Growth and Poverty in sub-Saharan Africa; Katajanokanlaituri 6 B: Helsinki, Finland, 2016; Volume 218.

52. FAO. Nigeria Agriculture at a Glance; Garki: Abuja, Nigeria, 2021.

53. Chapin Metz, H. Nigeria: A Country Study; GPO for the Library of Congress: Washington, DC, USA, 1991.

54. Ikuemonisan, E.; Mafimisebi, T.E.; Ajibefun, I.; Adenegan, K. Cassava production in Nigeria: Trends, instability and decomposition analysis (1970-2018). Heliyon 2020, 6, e05089. [CrossRef]

55. Ismaila, U.; Gana, A.S.; Tswanya, N.M.; Dogara, D. Cereals production in Nigeria: Problems, constraints and opportunities for betterment. Afr. J. Agric. Res. 2010, 5, 1341-1350.

56. United Nations Industrial Development Organization. Independent Country Evaluation; Federal Republic of Nigeria; FINAL REPORT; United Nations Industrial Development Organization: Vienna, Austria, 2008; Volume 2.

57. The Federal Republic of Nigeria Poverty Work Program. Poverty Reduction in Nigeria in the Last Decade. In Poverty Global Practice, Africa Region; World Bank: Washington, DC, USA, 2016.

58. FAOSTAT. Food and Agricultural Organization of the United Nations Statistics; FAOSTAT: Abuja, Nigeria, 2000.

59. NBS. General Household Survey in Nigeria (Living Standard Measurement Survey Wave 4); National Bureau of Statistics (NBS): Abuja, Nigeria, 2019.

60. NBS. Nigeria Bureau of Statistics—Consumption Expenditure Pattern in Nigeria; National Bureau of Statistics Central Business District, FCT: Abuja, Nigeria, 2019.

61. NBS. Nigeria Bureau of Statistics—Selected Food Prices; NBS: Abuja, Nigeria, 2019.

62. FMARD. Federal Ministry of Agriculture and Rural Development, Nigeria; FMARD: Abuja, Nigeria, 2017.

63. NAERLS. National Agricultural Extension and Research Liaison Services, Nigeria; NAERLS: Zaria, Nigeria, 2017.

64. NGCC. National Geomatics Center of China_GLOBELAND30 PROJECT; NGCC: Beijing, China, 2020.

65. INDDEX. International Dietary Data Expansion Project. In Data4Diets: Building Blocks for Diet-related Food Security Analysis; Tufts University: Boston, MA, USA, 2018.

66. NBS, Nigeria Bureau of Statistics. 2019 Poverty and Inequality in Nigeria Report; NBS, Nigeria Bureau of Statistics: Lagos, Nigeria, 2019.

67. Smith, L.C.; Subandoro, A. Measuring Food Security Using Household Expenditure Surveys; International Food Policy Research Institute (IFPRI): Washington, DC, USA, 2007; Volume 3.

68. Osabuohien, E.S.; Okorie, U.E.; Osabohien., R.A. Rice Production and Processing in Ogun State, Nigeria: Qualitative Insights from Farmers' Association; IGI Global: Hershey, PA, USA, 2018. 
69. Agada, M.; Igbokwe, E. Influence of Food Culture and Practices on Household Food Security in North Central Nigeria. J. Food Secur. 2016, 4, 36-41.

70. Iorlamen, T.R.; Abu, G.A.; Lawal, W.L. Assessment of expenditure on food among urban households and it's implication for food security: Evidence from Benue State, Nigeria. Afr. J. Food Agric. Nutr. Dev. 2014, 14, 8748-8760.

71. Olayemi, A.O. Effects of family size on household food security in Osun State, Nigeria. J. Asian J. Agric. Rural. Dev. 2012, 2, 136-141.

72. Qian, L.; Li, F.; Liu, H.; Wang, L.; McCarthy, B.; Jin, S. Rice vs. Wheat: Does staple food consumption pattern affect food waste in Chinese university canteens? Resour. Conserv. Recycl. 2022, 176, 105902. [CrossRef] 